\title{
Current Status and New Developments in Breast MRI
}

\author{
Katja C. Siegmann ${ }^{\mathrm{a}} \quad$ Bernhard Krämer $^{\mathrm{b}} \quad$ Claus Claussen $^{\mathrm{a}}$ \\ aDepartment of Diagnostic and Interventional Radiology, \\ ${ }^{b}$ Department of Obstetrics and Gynaecology, University Hospital Tuebingen, Germany
}

\section{Keywords}

Breast · MRI · Diffusion-weighted · 3 Tesla · Spectroscopy

\section{Summary}

Breast magnetic resonance imaging (MRI) is the most sensitive imaging modality for the detection of breast cancer. Its specificity is equivalent to that of mammography. Nowadays, breast MRI is an absolutely essential breast imaging method. Technical innovations allow dynamic contrast-enhanced (DCE) MRI of both breasts with high image quality. Thereby, DCE breast MRI should always be performed with regard to current standards. New quantitative techniques such as diffusion-weighted MRI are promising. However, they still have potential pitfalls, in particular with regard to the diagnosis of non-mass lesions and small breast lesions. Ongoing technical innovations can possibly help to further optimize breast MRI.

\section{Introduction}

The technique of contrast-enhanced magnetic resonance imaging (MRI) of the breast was developed about 25 years ago [1]. Fast T1-weighted gradient echo (GE) sequences made dynamic contrast-enhanced (DCE) breast MRI with satisfactory image quality possible $[2,3]$. First results were promising and reported sensitivity and specificity levels for breast cancer diagnosis of over 95\% [3]. Nowadays, DCE breast MRI is the most sensitive breast imaging modality. It is more sensitive than mammography and ultrasound and a combination of both. Its specificity corresponds to that of mammography $[4,5]$. Various efforts have been made to further improve the diagnostic performance of breast MRI. All of them aim to further increase the specificity of breast MRI

\author{
Schlüsselwörter \\ Mamma · MRT · Diffusionswichtung · 3 Tesla · Spektroskopie
}

\section{Zusammenfassung}

Die Magnet-Resonanz-Mammografie (MRM) ist das sensitivste Verfahren in der Detektion des Mammakarzinoms und zeigt eine der Mammografie gleichwertige Spezifität. Die MRM stellt heutzutage eine unverzichtbare Methode in der bildgebenden Mammadiagnostik dar. Technische Fortschritte erlauben mittlerweile eine hochqualitative Bildgebung mittels dynamischer kontrastangehobener MRM. Die Durchführung und Auswertung der MRM sollte stets unter Berücksichtigung derzeitiger Standards und empfohlener Indikationen erfolgen. Neue, quantitive Verfahren wie Diffusionswichtung (DW-MRT) versprechen potentiell eine noch zuverlässigere Diagnosestellung. Jedoch zeigen auch diese Methoden insbesondere bei der Diagnostik von kleinen Läsionen und solchen, die sich als segmentales Enhancement ohne eigentlichen Herdbefund darstellen, Schwächen. Möglicherweise können weitere technische Entwicklungen zur weiteren Optimierung der MRM beitragen.

by better differentiation of contrast-enhancing lesions [6]. This article summarizes the current status und the most promising new developments in breast MRI.

\section{Current Standard of Dynamic Contrast-Enhanced Breast MRI}

Technical aspects of recommended image acquisition have been published to standardize breast MRI $[5,7]$. The prerequisites for high quality breast MRI are a magnetic field strength of at least 1.5 Tesla $(\mathrm{T})$, gradients $\geq 20 \mathrm{mT} / \mathrm{m}$, and bilateral dedicated breast surface coils, preferably multichannel. Before the dynamic scan, a T2-weighted sequence with high spatial resolution is necessary to facilitate analysis of

\section{KARGER \\ Fax +497614520714 \\ Information@Karger.de}

www.karger.com (c) 2011 S. Karger GmbH, Freiburg

1661-3791/11/0062-0087\$38.00/0

Accessible online at:

www.karger.com/brc
Dr. Katja C. Siegman

University Hospital Tuebingen

Department of Diagnostic and Interventional Radiology

Hoppe-Seyler-Str. 3, 72076 Tübingen, Germany

Tel. +49 7071 29-82087, Fax -5845

katja.siegmann@med.uni-tuebingen.de 
structures with high T2 signal. Bilateral dynamic breast MRI should be preferably performed in the transverse plane to minimize motion artefacts and to allow delineation or exclusion of nipple or chest wall invasion. Fast T1-weighted spoiled GE pulse sequences make dynamic high resolution imaging possible. The optimal sequence is a compromise between high spatial resolution and high temporal resolution. It allows detailed depiction of lesion morphology and enhancement characteristics at the same time. Both details are necessary for differentiation of benign and malignant findings. Threedimensional (3D) GE pulse sequences provide technically stable high resolution images. The time of repetition should be as short as possible, the flip angle as large as possible (20-50 $)$, and the echo time should be set short and in-phase (4.6 msec at $1.5 \mathrm{~T})$. The field of view should cover both breasts $(320$ $380 \mathrm{~mm}$ ). For high spatial resolution, an acquisition matrix of $512 \times 512$ and a section thickness of $1-3 \mathrm{~mm}$ are recommended. Malignant lesions are characterised by early strong enhancement with subsequent plateau or wash-out. The analysis of the early post contrast series (after 60-120 s) is therefore most suitable for the detection of malignant lesions. To evaluate the lesions' enhancement characteristics, a temporal resolution of less than $120 \mathrm{~s}$ per acquisition, ideally $60 \mathrm{~s}$, should be used [5]. The entire dynamic scan should cover at least 6 min after contrast medium injection to detect possible wash-out in the late phase.

T1-shortening contrast agents (gadolinium chelates) are used for all breast MRI protocols. A dose of $0.1 \mathrm{mmol}$ per $\mathrm{kg}$ body weight is mostly recommended. The contrast agent should be injected automatically intravenously with a flow rate of $3 \mathrm{ml} / \mathrm{s}$ followed by a $20 \mathrm{ml}$ saline flush. The first postcontrast acquisition should be started immediately after contrast medium injection (during saline flush).

Hormonal stimulation can lead to increased enhancement of normal breast tissue [8-10]. In order to reduce the risk of hormonal-related false-positive enhancing lesions, the EUSOMA work group recommends that premenopausal women should undergo breast MRI preferably in the second or third week of the menstrual cycle, even if hormonal contraception is used [7]. In the case of postmenopausal women, hormone replacement therapy should be discontinued at least 4 weeks before breast MRI.

A dedicated workstation is necessary for data analysis of DCE breast MRI. Region-of-interest (ROI) analysis of enhancing lesions on subtraction images or fat-saturated images is necessary to assess kinetic data. Curve type measurements are useful as a diagnostic criterion in breast lesions irrespective of the method used [11].

Every lesion should be classified according to the breast imaging reporting and data system for breast MRI (MRI-BIRADS $^{\circledR}$ ) of the American College of Radiology (ACR) [12] to standardize the report and to determine the clinical approach [13]. Morphologic and kinetic lesion characteristics were used for lesion classification. The combination of differ- ent lesion criteria to form a total breast MRI score can be useful. Fischer et al. [14] developed a breast MRI score which can be translated into BI-RADS [15] and enables thereby a standardized BI-RADS classification with satisfying positive predictive value (PPV) of malignancy for each BI-RADS class [16].

\section{Current Indications of DCE Breast MRI}

Breast MRI is the most sensitive imaging modality for the detection of breast cancer. Recent studies show that MRI can even depict ductal carcinoma in situ (DCIS) (fig. 1) and invasive lobular carcinoma with high sensitivity [17-20]. To avoid false-positive enhancing lesions and subsequent unnecessary breast biopsies, breast MRI should be only used for certain indications. There are 7 useful indications for DCE breast MRI which are widely accepted [7, 21]: i) Local staging in women with known breast cancer; ii) Evaluation of response to neoadjuvant chemotherapy; iii) Detection of occult primary breast cancer; iv) Diagnosis of recurrent breast cancer after breast conserving treatment; v) Breast cancer screening of high risk women; vi) Diagnosis of patients with breast implants; vii) Characterisation of equivocal findings at conventional imaging.

Despite the high diagnostic accuracy of breast MRI, previous published studies failed to prove a reduction of the re-excision rate by preoperative MRI $[22,23]$. Both cited studies mainly suffer from rather low randomisation rates and patient selection bias. Therefore, the influence of preoperative breast MRI on the rate of re-excision as well as the influence of preoperative breast MRI on breast cancer recurrence are currently viewed controversially $[24,25]$.

\section{Contrast Agents}

DCE breast MRI has predominantly been performed with gadopentetate dimeglumine (Gd-DTPA; Magnevist ${ }^{\circledR}$, Bayer HealthCare Pharmaceuticals, Berlin, Germany). A dose of $0.1 \mathrm{mmol}$ per $\mathrm{kg}$ body weight is mostly recommended [6]. Until now, the reported diagnostic accuracies of DCE breast MRI using Gd-DTPA have been high [4]. Investigations of other contrast agents concern in particular gadobenate dimeglumine (Gd-BOPTA; MultiHance ${ }^{\circledR}$, Bracco Imaging Deutschland $\mathrm{GmbH}$, Konstanz, Germany). It possesses a 2-fold higher T1 relaxivity in vivo because of interactions of the gadolinium chelate with serum albumin. This increased T1 relaxivity of Gd-BOPTA translates into greater contrast enhancement which possibly results in improved lesion detection and lesion characterization compared to Gd-DTPA [2628]. However, these promising results were mainly published by 1 working group and partly financed by the contrast agent manufacturer. Therefore they need to be confirmed. The 

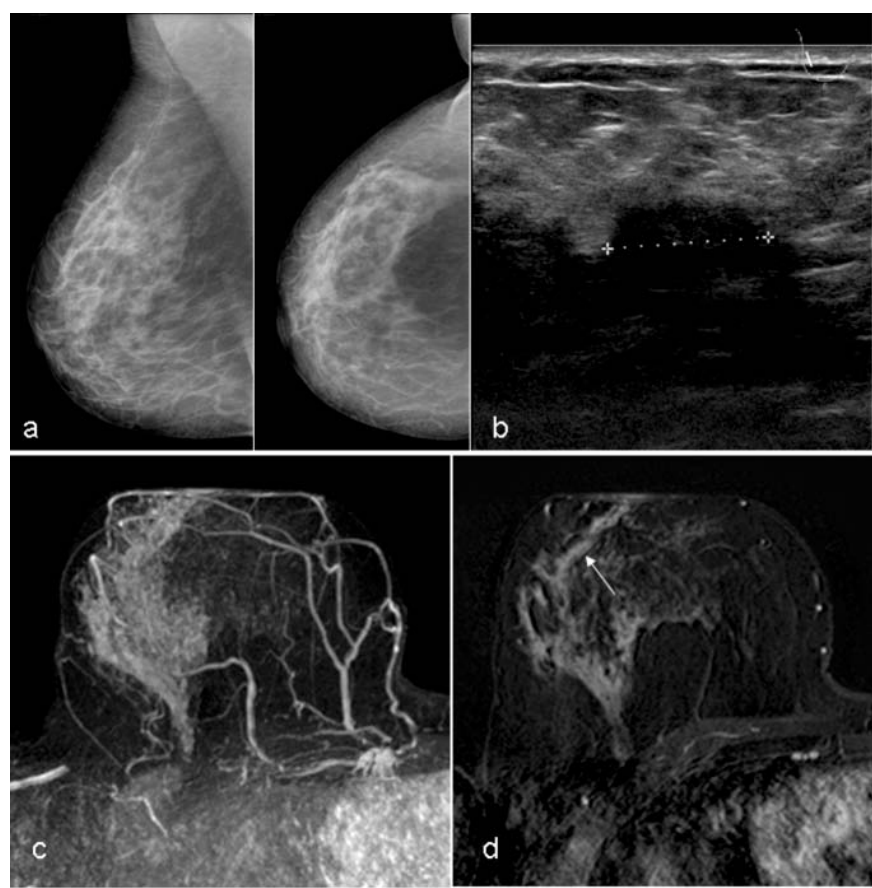

Fig. 1. Dynamic contrast-enhanced breast magnetic resonance imaging (MRI) showing a large ductal carcinoma in situ (DCIS) which was occult on a mammography and ultrasound. $\mathbf{b}$ Ultrasound of a patient who presented with a palpable lump in the right breast showed a 1.6- $\mathrm{cm}$ large lesion highly suspicious for malignancy (BI-RADS 5). c On the maximum intensity projection of subtracted early post-contrast T1-weighted gradient echo image, a 10-cm large non-mass enhancement highly suspicious for malignancy (BI-RADS 5) was detected in both outer quadrants of the right breast. d On single slice subtraction image a periductal enhancement highly suggestive for DCIS could be depicted (white arrow) which was histologically proven by MRI-guided breast biopsy. The final histology of the mastectomy specimen revealed a $1.5-\mathrm{cm}$ large invasive ductal carcinoma with extensive DCIS

diagnostic performance of other gadolinium chelates has not been sufficiently analysed. Therefore, further studies seem to be necessary to evaluate the influence of different contrast media on breast cancer diagnosis.

\section{Computer-Aided Diagnosis}

The first computer-aided diagnosis (CAD) system for breast MRI was launched in January 2003. Most CAD systems offer a combined analysis of lesion morphology and enhancement kinetics. Some studies evaluating CAD programs suggest that CAD analyses may improve diagnostic accuracy by improving specificity, while decreasing the time required for interpretation and the heterogeneity of radiologists' interpretations across varying levels of experience [29-31]. Others show an increased sensitivity by using CAD whereas the specificity decreased in cases of non-experienced readers [32]. The study of Williams et al. [33] showed that CAD helped significantly to discriminate benign from malignant lesions by defining a threshold enhancement. Other kinetic features did not further improve lesion discrimination. Baltzer et al. [11] showed that diagnostic accuracy was not significantly changed if kinetic measurements were performed by manual ROI placement, visual assessment, or CAD measurements. However, most of the above mentioned study results apply especially to lesions which present as a mass. Newell et al. [34] report that there is no significantly added diagnostic value of CAD if lesions present as non-mass-like enhancement. Therefore, more advanced algorithms are needed for those lesions. The sensitivity of CAD in the detection of DCIS is particularly poor and false-negative cases occur [33, 35].

CAD may be helpful in assessing changes in MRI enhancement profiles of tumours following chemotherapy. However, CAD-assessed significant enhancement following chemotherapy can be falsely negative for residual malignancy, and CAD tumour sizes can be less accurate than those measured by the radiologist in predicting the size of residual malignancy. Therefore, CAD may complement but should not replace the radiologist's assessment of tumours [36]. In conclusion, CAD can be helpful in lesion analysis but it does not have the potential to replace the experience of a breast radiologist neither in the initial diagnostic setting nor after neoadjuvant chemotherapy. Therefore, the EUSOMA working group [7] states that CAD may be beneficial, but it would be premature to recommend the routine use of such systems.

\section{Diffusion-Weighted Breast MRI}

Water molecules within tissue are not freely diffusing. Macromolecules, cell membranes, and other tissue microstructures hinder diffusion and thereby cause a reduction in the average diffusion displacement, compared to that of free water. This effective or apparent diffusion coefficient (ADC) can be quantitatively measured with diffusion-weighted (DW)-MRI. It is common to apply diffusion-weighting in 3 orthogonal directions. The ADC maps calculated from the 3 images are then averaged to obtain a mean ADC map, reducing the effects of anisotropic diffusion.

Malignant lesions show measurable differences in water diffusion because of their increased cellularity. They typically exhibit decreased ADC values compared to the surrounding unaffected tissue. Thereby malignant masses show lower ADC values than malignant non-mass-like lesions [37]. DWMRI techniques taking advantage of this characteristic can differentiate benign from malignant lesions [38-46] and may have the potential to increase the specificity of breast MRI in the diagnosis of breast cancer. However, due to reduced spatial resolution, the tumour visibility is worse using DWMRI compared to T1-weighted-GE or T2-weigthed turbo spin echo (TSE) sequences. Published values of sensitivity and specificity of DW-MRI vary from 80 to $98 \%$ and 46 to $93 \%$, respectively (table 1). A recent meta-analysis of several 
Table 1. Diagnostic performance of diffusion-weighted magnetic resonance imaging (DW-MRI) of the breast

\begin{tabular}{lcll}
\hline Study [ref.] & $\begin{array}{l}\text { Lesions, } \\
\mathrm{n}\end{array}$ & $\begin{array}{l}\text { Sensitivity, } \\
\%\end{array}$ & $\begin{array}{l}\text { Specificity, } \\
\%\end{array}$ \\
\hline Kinoshita et al., 2002 [39] & 22 & 93 & 46 \\
Guo et al., 2002 [38] & 52 & 93 & 88 \\
Woodhams et al., 2005 [40] & 191 & 95 & 46 \\
Rubesova et al., 2006 [41] & 110 & 86 & 86 \\
Wenkel et al., 2007 [42] & 69 & 98 & 93 \\
Marini et al., 2007 [43] & 81 & 80 & 81 \\
Baltzer et al., 2009 [44] & 65 & 87 & 83 \\
\hline
\end{tabular}

studies regarding breast DW-MRI on $1.5 \mathrm{~T}$ scanners confirmed the utility of ADC to distinguish between benign and malignant lesions with a pooled sensitivity of $89 \%$ and a specificity of $77 \%$ [45]. DW-MRI in combination with short tau inversion recovery (STIR) imaging shows similar values of sensitivity and specificity compared to DCE breast MRI [47]. This applies especially to the analysis of mass lesions [48]. Yabuuchi et al. [49] show a good performance of DW-MRI added to DCE breast MRI with high diagnostic accuracy also on non-mass-like breast lesions. Partridge et al. [37] showed that the differentiation of benign and malignant masses and lesions with non-mass-like enhancement by DW-MRI was not affected by lesion size.

Treatments that cause cells to shrink lead to early increase in ADC that can be predictive of the ultimate tumour response [6]. Therefore, DW-MRI may be able to offer earlier and more precise information on response to neoadjuvant treatment than DCE breast MRI and analysis of tumour size with regard to the response evaluation criteria in solid tumours (RECIST) [50, 51]. The results of a study by Pickles et al. [52] indicate that DW-MRI may provide a suitable biomarker capable of providing an indication of response to treatment prior to tumour size measurement.

However, the threshold ADC values determined for differentiation of benign and malignant breast lesions differ substantially between the study groups. Because of considerable overlap of ADC values in benign and malignant lesions, breast DW-MRI must remain a research tool until larger studies are performed to validate the above described findings. Standard DW-MRI protocols for breast MRI need to be established to ensure reproducibility at different sites. Overall, DW-MRI seems to be the most promising method of functional breast MRI and it is expected to enter clinical practice in the near future.

\section{Magnetic Resonance Spectroscopy}

Hydrogen $\left({ }^{1} \mathrm{H}\right)$ magnetic resonance spectroscopy (MRS) can be performed along with MRI in order to gain information about a lesion's chemical content. Since choline-containing compounds are implicated in the synthesis and metabolism of cell mem- branes, the standard interpretation of increases in total choline signal is increased cell turnover. MRS measurements of choline are feasible in the human breast, and show statistically significant differences between benign and malignant lesions with elevated levels of choline-containing compounds in neoplastic breast tissue. The disadvantages of MRS are the limited signalto-noise ratio and limited spectral resolution. Both are essential to separate important choline metabolites.

In one report, MRS provided a sensitivity of $100 \%$ and a specificity of $88 \%$ in breast cancer diagnosis [53]. A combination of DCE breast MRI and MRS may offer improved specificity compared to either modality alone $[54,55]$. In the study by Meisamy et al. [56], MRS in addition to DCE breast MRI resulted in increased sensitivity, specificity, and accuracy. In the study by Bartella et al. [57], the use of ${ }^{1} \mathrm{H}-\mathrm{MRS}$ as a supplement to breast MRI could significantly increase the PPV of biopsy for MRI-detected lesions with non-mass enhancement and could decrease the number of benign biopsies.

The reduction of the concentration of total choline-containing compounds on single-voxel ${ }^{1} \mathrm{H}$-MRS may be a useful indicator of response of locally advanced breast cancer to neoadjuvant chemotherapy $[58,59]$. Study results suggest that ${ }^{1} \mathrm{H}$-MRS may help predict response as early as $24 \mathrm{~h}$ after the first dose of neoadjuvant chemotherapy [57].

It may be true that choline is consistently detected in invasive ductal carcinoma, but DCIS are likely to be negative for choline at MRS [60]. Furthermore, elevated choline levels of invasive breast cancers can only be reliably detected in lesions larger than $1 \mathrm{~cm}$ in size [53, 60]. In addition, the single-voxel technique, which is most commonly used, allows only 1 lesion to be examined at a time [57]. At present, the routine use of MRS for the differentiation of benign and malignant breast lesions should not be suggested. Further studies are necessary to prove the diagnostic value of MRS in the clinical setting.

\section{Breast MRI at Higher Magnetic Field Strength - 3 T}

Higher field strength scanners provide an improved signal-tonoise ratio and spectral spreading. This leads to an improved image resolution of DCE breast MRI and MRS. Furthermore, these improvements can, potentially, lead to shortened acquisition times or increasing sensitivity and specificity for DWMRI and DCE breast MRI $[50,61]$. Pulse sequences must be modified from $1.5 \mathrm{~T}$ to $3 \mathrm{~T}$ to provide similar image contrast.

Only a few studies have performed a direct comparison between $1.5 \mathrm{~T}$ and $3 \mathrm{~T}$. They suggest that $3 \mathrm{~T}$ is at least equivalent and often better than $1.5 \mathrm{~T}$ [50]. One study prospectively compared the image quality and diagnostic performance of the data obtained at $3 \mathrm{~T}$ and $1.5 \mathrm{~T}$ in 37 women with 53 lesions [62]. Receiver operator characteristic (ROC) curves were calculated. The authors report improvement in diagnostic performance with a significantly improved ROC score of 0.98 at $3 \mathrm{~T}$ compared to 0.84 at $1.5 \mathrm{~T}(\mathrm{p}<0.05)$. 
However, there are also disadvantages of high-field breast MRI. The main barriers to $3 \mathrm{~T}$ breast imaging are increased inhomogeneity of the magnetic field, lengthening T1 and shortening T2, a higher specific absorption rate (SAR), and chemical shift artefacts [50]. Increased SAR may require modification of pulse sequences, which neutralizes some of the signal-to-noise ratio and temporal resolution gains at $3 \mathrm{~T}$. Increased magnetic field inhomogeneity can lead to reduced lesion enhancement and thereby reduced overall sensitivity of breast MRI [63, 64]. Altogether, DCE breast MRI at $3 \mathrm{~T}$ is feasible. Few studies report possible advantages of $3 \mathrm{~T}$ compared to $1.5 \mathrm{~T}[50,62]$, but these results are not proven yet. tial resolution. DCE breast MRI should always be performed with regard to current standards. New quantitative techniques such as DW-MRI can potentially improve the accuracy of breast MRI. CAD systems may further improve the specificity of DCE breast MRI and will be adopted in routine clinical practice especially among radiologists with limited experience in breast MRI. These new techniques still have potential pitfalls, in particular with regard to the diagnosis of non-mass lesions and small breast lesions. Overcoming the current limitations is primarily a technical challenge. Further work on acquisition and evaluation methods will be required to optimize a comprehensive multiparametric breast MRI examination within an acceptable scan time.

\section{Disclosure Statement}

None of the authors has any conflict of interest with regard to any sponsorship or funding arrangements relating to this work.
Breast MRI is the most sensitive imaging modality for the detection of breast cancer. Its specificity is equivalent to that of mammography. Recent advances in pulse sequences allow DCE breast MRI of both breasts with high temporal and spa-

\section{References}

1 Heywang SH, Hahn D, Schmidt H, Krischke I, Eiermann W, Bassermann R, Lissner J: MR imaging of the breast using gadolinium-DTPA. J Comput Assist Tomogr 1986;10:199-204.

$\checkmark 2$ Kaiser WA, Zeitler E: MR imaging of the breast: fast imaging sequences with and without Gd-DTPA. Preliminary observations. Radiology 1989; 170:681-686.

3 Ercolani P, Valeri G, Amici F: Dynamic MRI of the breast. Eur J Radiol 1998;27(suppl 2):S265-271.

$\checkmark 4$ Benndorf M, Baltzer PA, Vag T, Gajda M, Runnebaum IB, Kaiser WA: Breast MRI as an adjunct to mammography: does it really suffer from low specificity? A retrospective analysis stratified by mammographic BI-RADS classes. Acta Radiol 2010;51:715-721.

5 Kuhl CK: The current status of breast MR imaging. Part 1. Choice of technique, image interpretation, diagnostic accuracy, and transfer to clinical practice. Radiology 2007;244:356-378.

6 Sinha S, Sinha U: Recent advances in breast MRI and MRS. NMR Biomed 2009;22:3-16.

7 Sardanelli F, Boetes C, Borisch B, Decker T, Federico M, Gilbert FJ, Helbich T, HeywangKöbrunner SH, Kaiser WA, Kerin MJ, Mansel RE, Marotti L, Martincich L, Mauriac L, MeijersHeijboer H, Orecchia R, Panizza P, Ponti A, Purushotham AD, Regitnig P, Del Turco MR, Thibault F, Wilson R: Magnetic resonance imaging of the breast: recommendations from the EUSOMA working group. Eur J Cancer 2010;46:12961316.

$>8$ Kuhl CK, Bieling HB, Gieseke J, Kreft BP, Sommer T, Lutterbey G, Schild HH: Healthy premenopausal breast parenchyma in dynamic contrast-enhanced MR imaging of the breast: normal contrast medium enhancement and cyclical-phase dependency. Radiology 1997;203:137-144.

$\checkmark 9$ Mueller-Schimpfle M, Ohmenhaüser K, Stoll P, Dietz K, Claussen CD: Menstrual cycle and age: influence on parenchymal contrast medium enhancement in MR imaging of the breast. Radiology 1997;203:145-149.
10 Baltzer PA, Dietzel M, Vag T, Burmeister H, Gajda M, Camara O, Pfleiderer SO, Kaiser WA: Clinical MR mammography: impact of hormonal status on background enhancement and diagnostic accuracy. Rofo 2011;Epub ahead of print.

11 Baltzer PA, Freiberg C, Beger S, Vag T, Dietzel M, Herzog AB, Gajda M, Camara O, Kaiser WA: Clinical MR-mammography: are computer-assisted methods superior to visual or manual measurements for curve type analysis? A systematic approach. Acad Radiol 2009;16:1070-1076.

12 American College of Radiology (ACR): Breast Imaging Reporting and Data System ${ }^{\circledR}$ (BI-RADS ${ }^{\circledR}$ ) Atlas. 4th ed. Reston, VA, American College of Radiology, 2003.

13 Agrawal G, Su MY, Nalcioglu O, Feig SA, Chen JH: Significance of breast lesion descriptors in the ACR BI-RADS MRI lexicon. Cancer 2009;115:1363-1380.

14 Fischer U, Kopka L, Grabbe E: Breast carcinoma: effect of preoperative contrast-enhanced MR imaging on the therapeutic approach. Radiology 1999;213:881-888.

15 Baum F, Fischer U, Vosshenrich R, Grabbe E: Classification of hypervascularized lesions in CE MR imaging of the breast. Eur Radiol 2002;12:1087-1092.

16 Siegmann KC, Moron HU, Baur A, Hahn M, Vogel U, Claussen CD, Bitzer M: Diagnostic value of a breast MRI score for the prediction of malignancy of breast lesions detected solely with MRI. Rofo 2009;181:1-8.

17 Schelfout K, Van Goethem M, Kersschot E, Verslegers I, Biltjes I, Leyman P, Colpaert C, Thienpont L, Van den Haute J, Gillardin JP, Tjalma W, Buytaert P, De Schepper A: Preoperative breast MRI in patients with invasive lobular breast cancer. Eur Radiol 2004;14:1209-1216.
8 Menell JH, Morris EA, Dershaw DD, Abramson AF, Brogi E, Liberman L: Determination of the presence and extent of pure ductal carcinoma in situ by mammography and magnetic resonance imaging. Breast J 2005;11:382-390.

19 Kuhl CK, Schrading S, Bieling HB, Wardelmann E, Leutner CC, Koenig R, Kuhn W, Schild HH MRI for diagnosis of pure carcinoma in situ: a prospective observational study. Lancet 2007;370:485492.

20 Mann RM: The effectiveness of MR imaging in the assessment of invasive lobular carcinoma of the breast. Magn Reson Imaging Clin N Am 2010;18:259-276.

21 Kuhl CK: The current status of breast MR imaging. Part 2. Clinical applications. Radiology 2007;244:672-690.

22 Turnbull L, Brown S, Harvey I, Olivier C, Drew P, Napp V, Hanby A, Brown J: Comparative effectiveness of MRI in breast cancer (COMICE) trial: a randomised controlled trial. Lancet 2010;375:563-571.

23 Peters NH, van Esser S, van den Bosch MA, Storm RK, Plaisier PW, van Dalen T, Diepstraten SC, Weits T, Westenend PJ, Stapper G, FernandezGallardo MA, Borel Rinkes IH, van Hillegersberg R, Mali WP, Peeters PH: Preoperative MRI and surgical management in patients with nonpalpable breast cancer: the MONET - randomised controlled trial. Eur J Cancer 2011;47:879-886.

24 Fischer U, Zachariae O, Baum F, von Heyden D, Funke M, Liersch T: The influence of preoperative MRI of the breasts on recurrence rate in patients with breast cancer. Eur Radiol 2004;14:1725-1731.

25 Solin LJ, Orel SG, Hwang W-T, Harris EE, Schnall MD: Relationship of breast magnetic resonance imaging to outcome after breast-conservation treatment with radiation for women with early-stage invasive breast carcinoma or ducal carcinoma in situ. J Clin Oncol 2008;26:386-291. 
26 Knopp MV, Bourne MW, Sardanelli F, Wasser MN, Bonomo L, Boetes C, Müller-Schimpfle $M$, Hall-Craggs MA, Hamm B, Orlacchio A, Bartolozzi C, Kessler M, Fischer U, Schneider G, Oudkerk M, Teh WL, Gehl HB, Salerio I, Pirovano G, La Noce A, Kirchin MA, Spinazzi A: Gadobenate dimeglumine-enhanced MRI of the breast: analysis of dose response and comparison with gadopentetate dimeglumine. Am J Roentgenol 2003; 181:663-676.

27 Pediconi F, Catalano C, Occhiato R, Venditti F, Fraioli F, Napoli A, Kirchin MA, Passariello R: Breast lesion detection and characterization at contrast-enhanced MR mammography: gadobenate dimeglumine versus gadopentetate dimeglumine. Radiology 2005;237:45-56.

28 Martincich L, Faivre-Pierret M, Zechmann CM, Corcione S, van den Bosch HC, Peng WJ, Petrillo A, Siegmann KC, Heverhagen JT, Panizza P, Gehl HB, Diekmann F, Pediconi F, Ma L, Gilbert FJ, Sardanelli F, Belli P, Salvatore M, Kreitner KF, Weiss CM, Zuiani C: Multicenter, double-blind, randomized, intraindividual crossover comparison of gadobenate dimeglumine and gadopentetate dimeglumine for breast MR imaging (DETECT Trial). Radiology 2011;258:396-408.

-29 Lehman CD, Peacock S, DeMartini WB, Chen $\mathrm{X}$ : A new automated software system to evaluate breast MR examinations: improved specificity without decreased sensitivity. Am J Roentgenol 2006;187:51-56.

30 Meinel LA, Stolpen AH, Berbaum KS, Fajardo LL, Reinhardt JM: Breast MRI lesion classification: improved performance of human readers with a backpropagation neural network computer-aided diagnosis (CAD) system. J Magn Reson Imaging 2007;25:89-95.

-31 Meeuwis C, van de Ven SM, Stapper G, Fernandez Gallardo AM, van den Bosch MA, Mali WP, Veldhuis WB: Computer-aided detection (CAD) for breast MRI: evaluation of efficacy at 3.0 T. Eur Radiol 2010;20:522-528.

32 Renz DM, Baltzer PA, Kullnig PE, Böttcher J, Vag T, Gajda M, Camara O, Runnebaum IB, Kaiser WA: Clinical value of computer-assisted analysis in MR mammography. A comparison between two systems and three observers with different levels of experience. Rofo 2008;180:968-976.

33 Williams TC, DeMartini WB, Partridge SC, Peacock S, Lehman CD: Breast MR imaging: computer-aided evaluation program for discriminating benign from malignant lesions. Radiology 2007;244:94-103.

>34 Newell D, Nie K, Chen JH, Hsu CC, Yu HJ, Nalcioglu O, Su MY: Selection of diagnostic features on breast MRI to differentiate between malignant and benign lesions using computer-aided diagnosis: differences in lesions presenting as mass and non-mass-like enhancement. Eur Radiol 2010;20:771-781.

$\checkmark 35$ Arazi-Kleinman T, Causer PA, Jong RA, Hill K, Warner E: Can breast MRI computer-aided detection (CAD) improve radiologist accuracy for lesions detected at MRI screening and recommended for biopsy in a high-risk population? Clin Radiol 2009;64:1166-1174.

36 Demartini WB, Lehman CD, Peacock S, Russell MT: Computer-aided detection applied to breast MRI: assessment of CAD-generated enhancement and tumor sizes in breast cancers before and after neoadjuvant chemotherapy. Acad Radiol 2005;12:806-814.
7 Partridge SC, Mullins CD, Kurland BF, Allain MD, DeMartini WB, Eby PR, Lehman CD: Apparent diffusion coefficient values for discriminating benign and malignant breast MRI lesions: effects of lesion type and size. Am J Roentgenol 2010;194:1664-1673.

38 Guo Y, Cai YQ, Cai ZL, Gao YG, An NY, Ma L, Mahankali S, Gao JH: Differentiation of clinically benign and malignant breast lesions using diffusion-weighted imaging. J Magn Reson Imaging 2002;16:172-178.

39 Kinoshita T, Yashiro N, Ihara N, Funatu H, Fukuma E, Narita M: Diffusion-weighted half-Fourier single-shot turbo spin echo imaging in breast tumors: differentiation of invasive ductal carcinoma from fibroadenoma. J Comput Assist Tomogr 2002;26:1042-1046.

40 Woodhams R, Matsunaga K, Kan S, Hata H, Ozaki M, Iwabuchi K, Kuranami M, Watanabe M, Hayakawa K: ADC mapping of benign and malignant breast tumors. Magn Reson Med Sci 2005;4:35-42.

41 Rubesova E, Grell AS, De Maertelaer V, Metens T, Chao SL, Lemort M: Quantitative diffusion imaging in breast cancer: a clinical prospective study. J Magn Reson Imaging 2006;24:319-324.

42 Wenkel E, Geppert C, Schulz-Wendtland R, Uder M, Kiefer B, Bautz W, Janka R: Diffusion weighted imaging in breast MRI: comparison of two different pulse sequences. Acad Radiol 2007;14:1077-1083.

43 Marini C, Iacconi C, Giannelli M, Cilotti A, Moretti M, Bartolozzi C: Quantitative diffusion-weighted MR imaging in the differential diagnosis of breast lesion. Eur Radiol 2007;17:2646-2655.

44 Baltzer PA, Renz DM, Herrmann KH, Dietzel M, Krumbein I, Gajda M, Camara O, Reichenbach JR, Kaiser WA: Diffusion-weighted imaging (DWI) in MR mammography (MRM): clinical comparison of echo planar imaging (EPI) and half-Fourier singleshot turbo spin echo (HASTE) diffusion techniques. Eur Radiol 2009;19:1612-1620.

45 Tsushima Y, Takahashi-Taketomi A, Endo K: Magnetic resonance (MR) differential diagnosis of breast tumors using apparent diffusion coefficient (ADC) on 1.5-T. J Magn Reson Imaging 2009;30:249-255.

46 Iacconi C: Diffusion and perfusion of the breast. Eur J Radiol 2010;76:386-390.

47 Kuroki-Suzuki S, Kuroki Y, Nasu K, Nawano S, Moriyama N, Okazaki M: Detecting breast cancer with non-contrast MR imaging: combining diffusion-weighted and STIR imaging. Magn Reson Med Sci 2007;6:21-27.

48 Baltzer PA, Benndorf M, Dietzel M, Gajda M, Camara O, Kaiser WA: Sensitivity and specificity of unenhanced MR mammography (DWI combined with T2-weighted TSE imaging, ueMRM) for the differentiation of mass lesions. Eur Radiol 2010;20:1101-1110.

49 Yabuuchi H, Matsuo Y, Kamitani T, Setoguchi T, Okafuji T, Soeda H, Sakai S, Hatakenaka M, Kubo M, Tokunaga E, Yamamoto $\mathrm{H}$, Honda $\mathrm{H}$ : Non-mass-like enhancement on contrast-enhanced breast MR imaging: lesion characterization using combination of dynamic contrast-enhanced and diffusion-weighted MR images. Eur J Radiol 2010; 75:e126-132

50 Arlinghaus LR, Li X, Levy M, Smith D, Welch EB, Gore JC, Yankeelov TE: Current and future trends in magnetic resonance imaging assessments of the response of breast tumors to neoadjuvant chemotherapy. J Oncol 2010;2010. pii: 919620. Epub ahead of print.
Thoeny HC, Ross BD: Predicting and monitoring cancer treatment response with diffusion-weighted MRI. J Magn Reson Imaging 2010;32:2-16.

52 Pickles MD, Gibbs P, Lowry M, Turnbull LW: Diffusion changes precede size reduction in neoadjuvant treatment of breast cancer. Magn Reson Imaging 2006;24:843-847.

53 Bartella L, Morris EA, Dershaw DD, Liberman L, Thakur SB, Moskowitz C, Guido J, Huang W: Proton MR spectroscopy with choline peak as malignancy marker improves positive predictive value for breast cancer diagnosis: preliminary study. Radiology 2006;239:686-692.

54 Jacobs MA, Barker PB, Argani P, Ouwerkerk R, Bhujwalla ZM, Bluemke DA: Combined dynamic contrast enhanced breast MR and proton spectroscopic imaging: a feasibility study. J Magn Reson Imaging 2005;21:23-28.

55 Bolan PJ, Nelson MT, Yee D, Garwood M Imaging in breast cancer: magnetic resonance spectroscopy. Breast Cancer Res 2005;7:149-152.

56 Meisamy S, Bolan PJ, Baker EH, Pollema MG, Le CT, Kelcz F, Lechner MC, Luikens BA, Carlson RA, Brandt KR, Amrami KK, Nelson MT, Everson LI, Emory TH, Tuttle TM, Yee D, Garwood M: Adding in vivo quantitative $1 \mathrm{H}$ MR spectroscopy to improve diagnostic accuracy of breast MR imaging: preliminary results of observer performance study at $4.0 \mathrm{~T}$. Radiology 2005;236:465-475.

57 Bartella L, Huang W: Proton (1H) MR spectroscopy of the breast. Radiographics 2007;27(suppl 1):S241-252.

58 Jagannathan NR, Kumar M, Seenu V, Coshic O, Dwivedi SN, Julka PK, Srivastava A, Rath GK Evaluation of total choline from in-vivo volume localized proton MR spectroscopy and its response to neoadjuvant chemotherapy in locally advanced breast cancer. Br J Cancer 2001;84:1016-1022.

59 Meisamy S, Bolan PJ, Baker EH, Bliss RL, Gulbahce E, Everson LI, Nelson MT, Emory TH, Tuttle TM, Yee D, Garwood M: Neoadjuvant chemotherapy of locally advanced breast cancer: predicting response with in vivo (1)H MR spectroscopy - a pilot study at 4 T. Radiology 2004:233:424-431.

60 Yeung DK, Yang WT, Tse GM: Breast cancer: in vivo proton MR spectroscopy in the characterization of histopathologic subtypes and preliminary observations in axillary node metastases. Radiology 2002;225:190-197.

61 Kuhl CK, Träber F, Gieseke J, Drahanowsky W, Morakkabati-Spitz N, Willinek W, von Falkenhausen M, Manka C, Schild HH: Whole-body highfield-strength (3.0-T) MR imaging in clinical practice. Part II. Technical considerations and clinical applications. Radiology 2008;247:16-35.

62 Kuhl CK, Jost P, Morakkabati N, Zivanovic O, Schild HH, Gieseke J: Contrast-enhanced MR imaging of the breast at 3.0 and $1.5 \mathrm{~T}$ in the same patients: initial experience. Radiology 2006;239:666-676.

63 Kuhl CK, Kooijman H, Gieseke J, Schild HH: Effect of B1 inhomogeneity on breast MR imaging at 3.0 T. Radiology 2007;244:929-930.

64 Azlan CA, Di Giovanni P, Ahearn TS, Semple SIK, Gilbert FJ, Redpath TW: B1 transmissionfield inhomogeneity and enhancement ratio errors in dynamic contrast-enhanced MRI (DCEMRI) of the breast at 3T. J Magn Reson Imaging 2010;31;234-239. 